\title{
THE OCCURRENCE OF FORMICA FUSCA L. IN SUMATRA.
}

\section{By William Morton Wheeler.}

In a preceding number of Psyche (Vol. 29, Aug. 1922, p. 175) I cited the occurrence of two common North American ants, Formica fusca L. and F. neogagates Emery, as having been taken by Dr. J. W. Chapman at Dumaguete, on the Island of Negros in the Philippines, and conjectured that they might have been introduced by commerce. Recently I have come to doubt the provenience of the specimens to which I referred. It seems that when he left the Bussey Institution to teach at the Silliman Institute in Dumaguete, Dr. Chapman was supplied by our laboratory with a number of empty vials to be used in collecting ants and other insects. Possibly two of these vials contained some specimens of $F$. fusca and neogagates that had been collected near Boston by one of the students and had been accidentally included among the material amassed by Dr. Chapman near the Silliman Institute. Since all this material was collected in a small area he did not provide the individual vials with locality labels. Until, therefore, the species of Formica above mentioned are again taken at Dumaguete, it is inadvisable to include them among the Philippine ant-fauna. No such doubt, however, can arise in regard to the species of Formica discussed in the following paragraphs.

Among a number of ants collected for me by Dr. David Fairchild and his son Graham Fairchild in Northern Sumatra, I find a series of twelve workers, which evidently belong to the common circumpolar Formica fusca, though they may be regarded as representing a distinct variety, var. fairchildi var. nov. These specimens were taken by Dr. Fairchild March 8th, 1926 above Kota Dah, at an altitude of $4000 \mathrm{ft}$., in a pine forest. Careful comparison with many specimens of the typical fusca reveals only the following slight differences: Body averaging slightly smaller $(4-5 \mathrm{~mm}$.); funicular joints of the antennæ a little shorter. Border of petiole distinctly sharper and more compressed. Bristles on the flexor surfaces of the middle and 
hind tibia stouter, less reclinate and more conspicuous. Pubescence much as in the true fusca, but finer and somewhat more dilute on the upper surface of the gaster, but distinctly longer on its sides and venter. The gaster is somewhat more shining and metallic, more as in the North American var. subcenescens Emery. The color is a deeper black than in fusca and the legs and palpi are more blackish, the mandibles and antennæ somewhat deeper red. One of the specimens has distinct bluish reflections like the Mexican $F$. subcyanea Wheeler. The male and female, when discovered, will probably exhibit additional differences.

We must, I believe, regard the var. fairchildi as a true tropical relict and not as a recent importation. Its occurrence in a remote locality, at a considerable altitude and among pines makes the latter supposition very improbable. It is quite different from the var. japonica Motschulsky from Japan and China, a form which we might, perhaps, expect to find in Indonesia. The present wide distribution of fusca and its many varieties throughout northern North America and Eurasia, and its very close relationship, if not identity, with F. flori Mayr of the Baltic Amber (Lower Oligocene Tertiary) suggest an even wider distribution during the geologic past. Further investigations at high altitudes in Sumatra and possibly also in Java and Borneo may show that fusca has survived also in other localities in these tropical islands. A somewhat similar case is presented by $F$. picea Nylander, a peat-bog ant which is widely distributed over northern Eurasia and as far south as Switzerland and Thibet, though it is not known to occur in North America or Japan. In 1913 Forel described from Taihorin, on the island of Formosa, a variety of this ant (formose) which like the above described fairchildi would seem to be a tropical relict. 

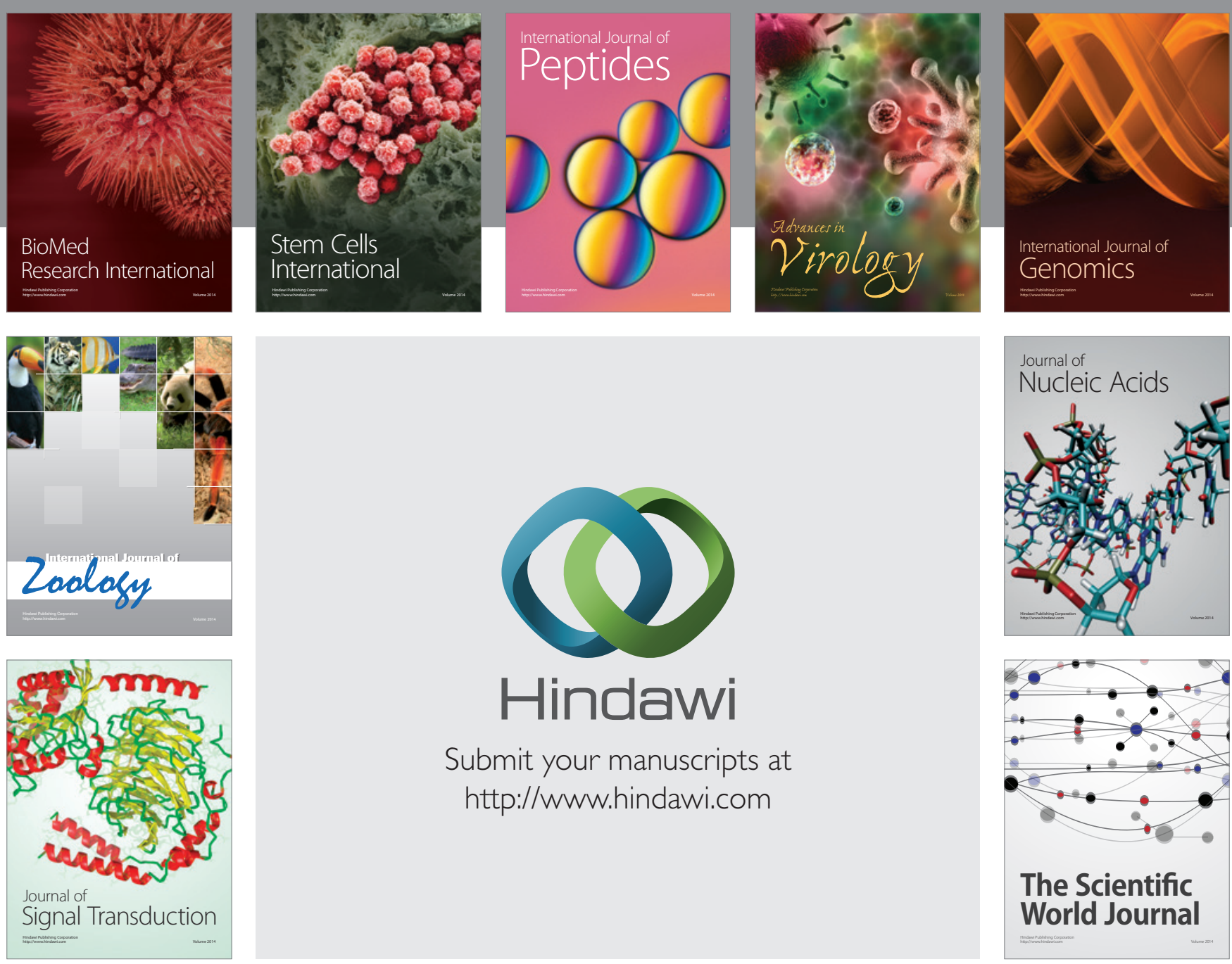

Submit your manuscripts at

http://www.hindawi.com
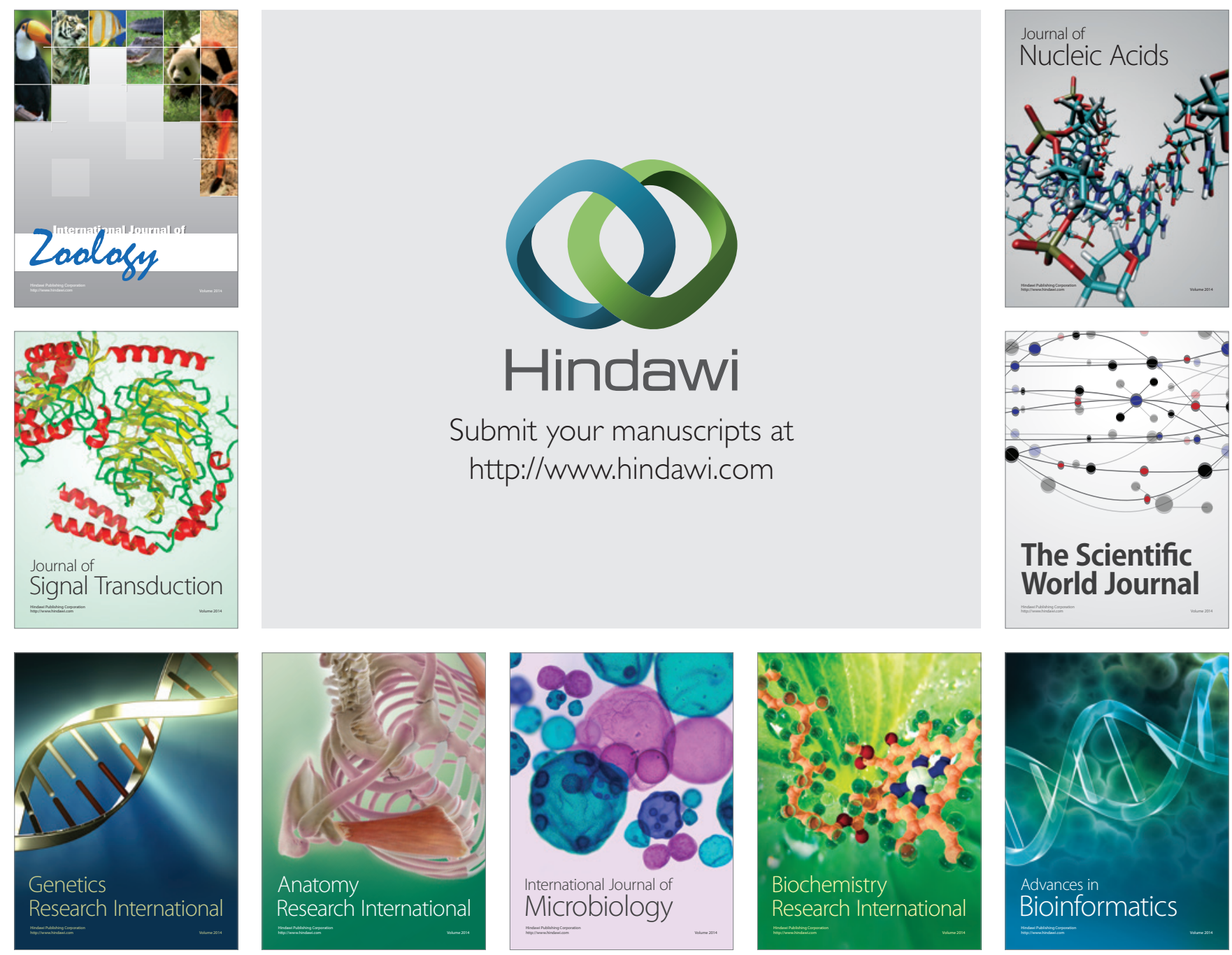

The Scientific World Journal
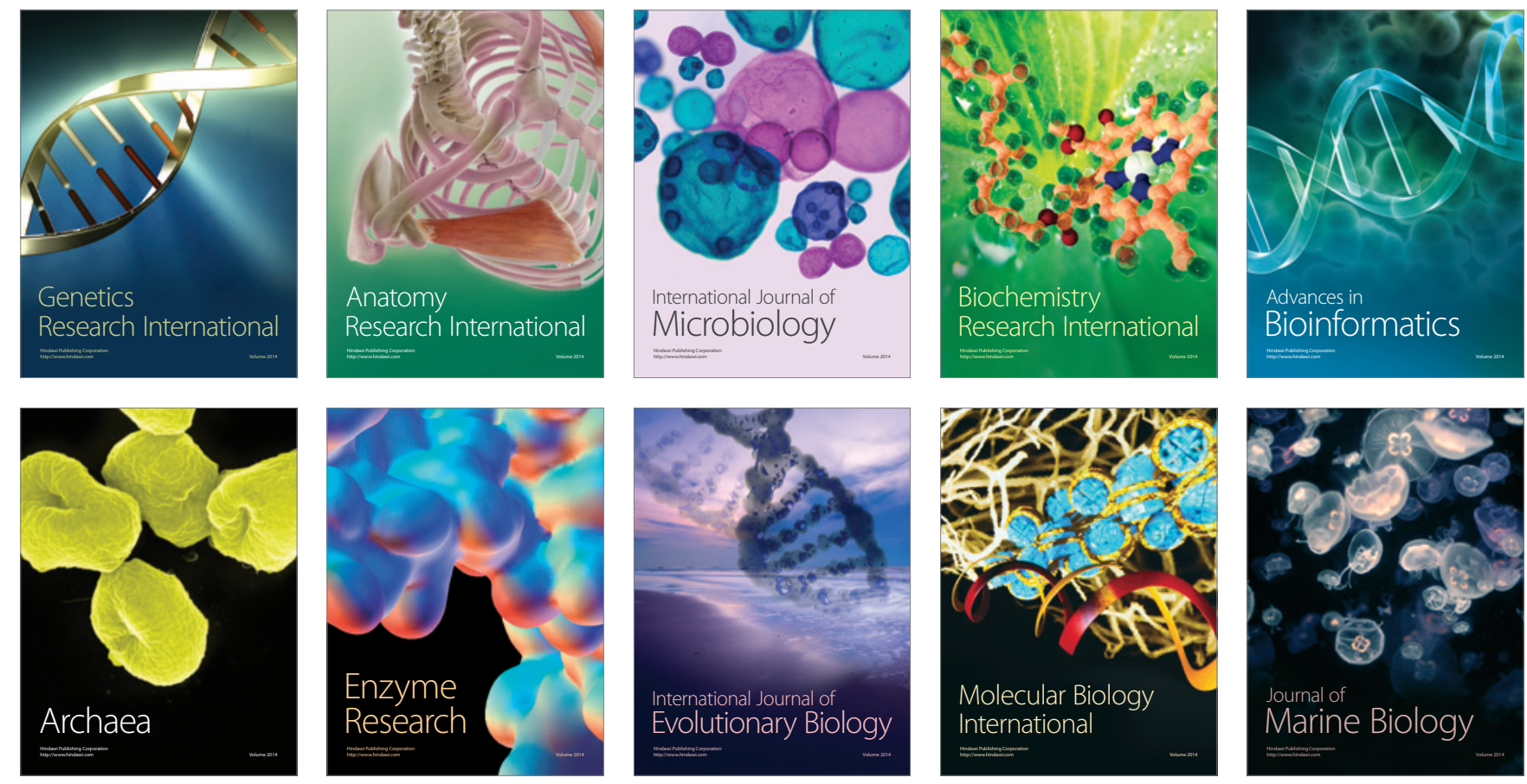